\title{
Automatic Blast Humidity Control* (Instrumentation and Control of Blast Furnaces)
}

\author{
Report of the Instrumentation Division, the Joint Research Society
}

\author{
By Kan-ichirō Katsura** and Takashi Isobe***
}

\section{Introduction}

The blast humidity control of a blast furnace is that which maintains the moisture content of the blast air to a fixed desired value by controlling the flow rate of steam injected into blast air duct automatically.

Such steam injection has been tried and studied since 1940, and it has been known that the humidity control is effectual in keeping good furnace condition.

Steam is changed to $\mathrm{CO}$ and $\mathrm{H}_{2}$ when it gets into the blast furnace.

$$
\mathrm{H}_{2} \mathrm{O}+\mathrm{C}=\mathrm{CO}+\mathrm{H}_{2}-27.840 \mathrm{Cal}
$$

Since this is an endothermic reaction, it has an effect in lowering the furnace temperature, but as a result of growing the concentration of reducing gas they can get saving cokes and increasing production of pig iron.

While, it is said that the oxygen enrichment control - control system in which oxygen is added automatically to blast air - is very effectual, especially when it is used in conjunction with the humidity control.

These controls are important topics concerning automatic control technology in steel plants. This report mentions the constitution and structure of humidity control, with actual construction and maintenance problems, and with short references to the oxygen enrichment control, on the basis of many reports that have been brought to the conferences of the Instrumentation Division, the Joint Research Society, The Iron and Steel Institute of Japan.

\section{Constitution}

\section{Measuring Methods of Humidity}

The well-known method of measuring humidity is the "wet and dry bulb hygrometer", which consists of two thermometers, one with a wet bulb and the other with a dry bulb (Fig. 1). They can measure the humidity by observing the temperature difference between the wet and dry bulb, according to Sprung's formula :

$$
p=p_{w}-A \cdot P\left(t-t_{w}\right)
$$

$p: \quad$ Vapor pressure in atmospheric air $(\mathrm{mm} \mathrm{Hg}$ )

$p_{w}$ : Maximum vapor pressure at temperature $t_{w} \quad(\mathrm{~mm} \mathrm{Hg})$

$P: \quad$ Atmospheric pressure $(\mathrm{mm} \mathrm{Hg})$

$t$ : Atmospheric temperature (temperature indicated by dry bulb

$t_{w}:$ Wet bulb temperature

A : Hygrometer constant

Fig. 2 shows a wet and dry bulb hygrometer modified for industrial use. This is a humidity measuring head, containing wet and dry bulbs in the chamber. Measuring gas, a part of the blast air in this case, flows through this chamber, and its humidity is measured by an electric resistance thermometer. The electric resistance thermometer has a fine platinum wire in the measuring bulb, and by the change in its resistance they can determine the temperature.

The measuring head is connected to an indicating or recording instrument, installed by a wire in the control center room. The whole circuit is shown in Fig. 3.

A thermostat in the measuring chamber controls the temperature of the measuring gas, because the temperature of the blast air is so high that the temperature of the measuring gas $(t)$ is apt to fluctuate and cause

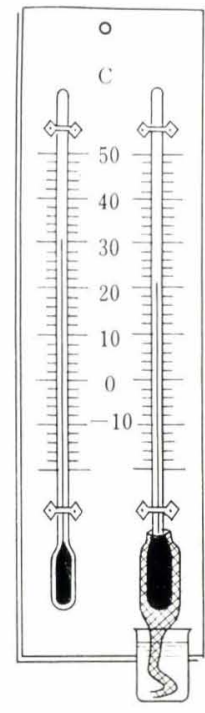

Fig. 1. Wet and dry bulb hygrometer

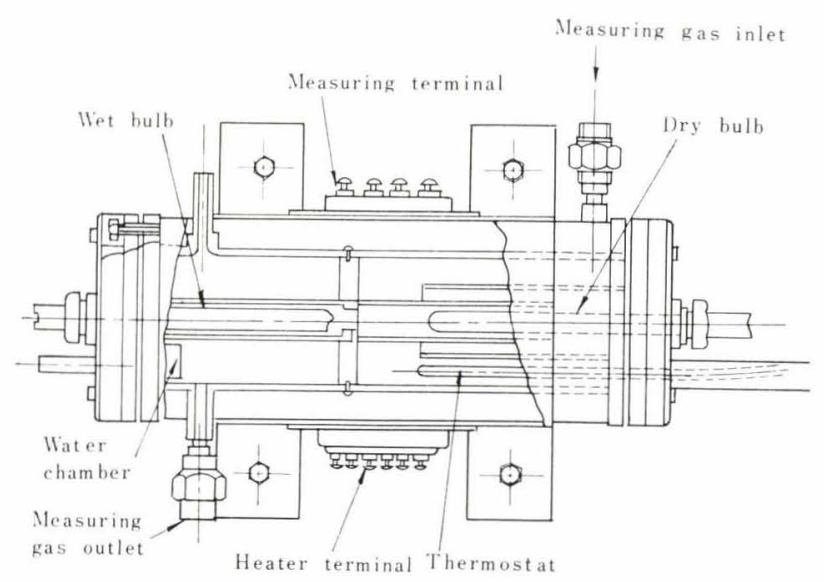

Fig. 2. Measuring head of industrial wet and dry bulb hygrometer

* Japanese text was printed in Tetsu-to-Hagané (Journal, Iron \& Steel Institute, Japan), 48 (1962), $14,1774-1792$.

** Chairman of the Instrumentation Division, the Joint Research Society, The Iron and Steel Institute of Japan.

*** Vice-Chairman of the Instrumentation Division, the Joint Research Society, The Iron and Steel Institute of Japan. 
errors in measuring.

The measuring time lag of this type of instrument is probably as follows:

$\begin{array}{ll}\text { Time constant } & 30-50 \mathrm{sec} . \\ \text { Dead time } & 10 \mathrm{sec} .\end{array}$

Lithium-chloride solution hygrometer is a fairly new device for measuring humidity and is widely used as an industrial instrument.

Solution of lithium-chloride $(\mathrm{LiCl})$ has a peculiar water vapor pressure depending on its concentration, and if the atmospheric vapor pressure is higher than its own vapor pressure, the solution will absorb vapor from the air, but if the atmospheric vapor pressure is lower than the vapor pressure of the solution, it will evaporate vapor in the air. This phenomenon has an equilibrium point which is dependent on the concentration and temperature of the solution and vapor pressure in the air. At the equilibrium point, as there is neither absorption nor evaporation, the humidity in the air can be known by measuring the temperature of the solution.

This is the principle of the $\mathrm{LiCl}$ hygrometer and Fig. 4 shows an industrial type measuring head. The solu-

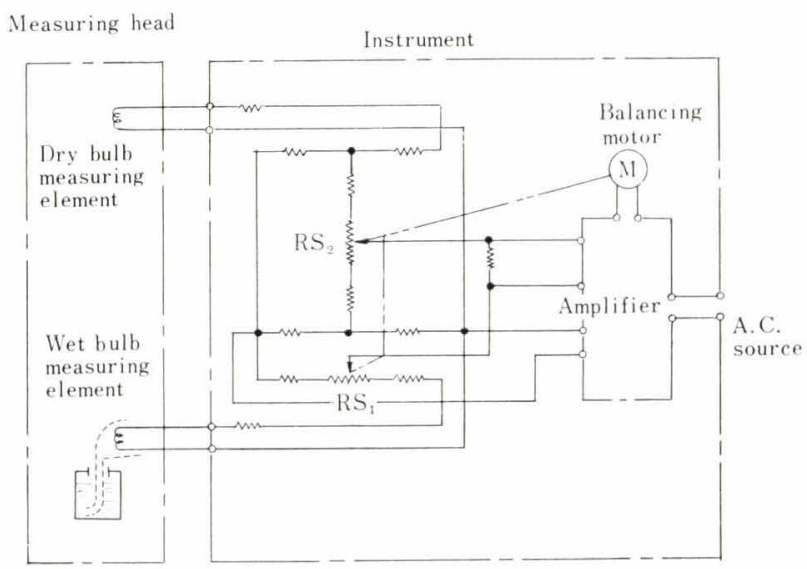

Fig. 3. Measuring circuit of industrial wet and dry bulb hygrometer

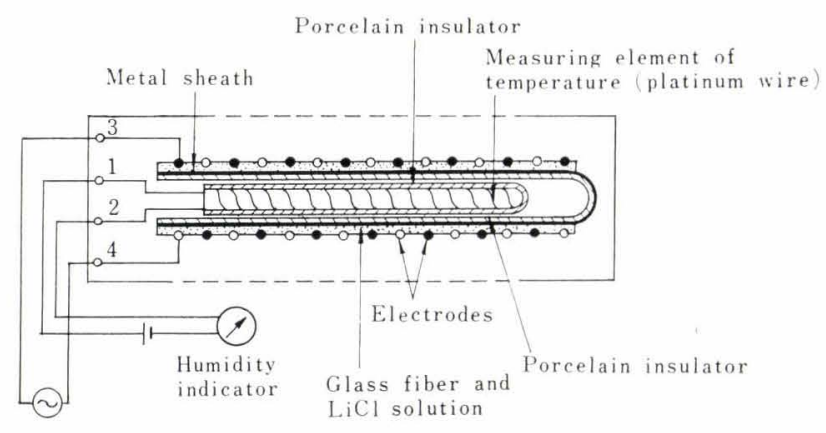

Electric

source

Fig. 4. Measuring head of LiCl hygrometer tion is sunk into a cotton gauze or into glass fiber between electrodes which are connected to an electric source, and the current flows through the solution. And by its Joule's heat, the solution is warmed and approaches the equilibrium point. The equilibrium temperature is measured by a platinum resistance thermometer in the measuring head. Fig. 5 shows the measuring circuit and Fig. 6 shows the active range of this type of instrument.

Another measuring method, used for the blast humidity control is the "gas density-ratio type" hygrometer. Fig. 7 shows the structure of it. There are two chambers identical in size, containing a primary and secondary wheels. One is the gas chamber, through which measuring gas flows, and the other is the air chamber, through which dry air flows as standard gas.

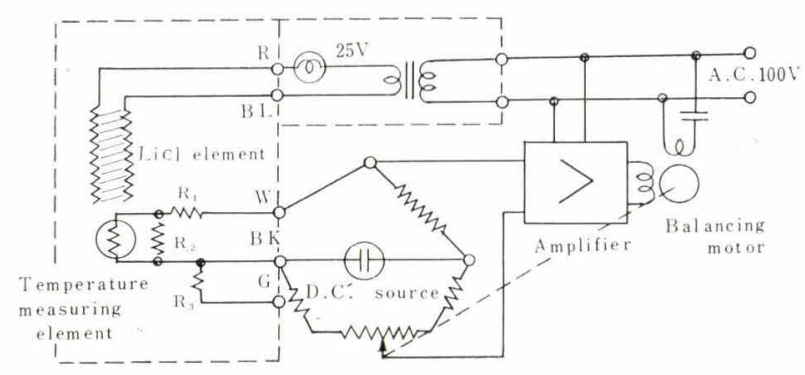

Fig. 5. Measuring circuit of $\mathrm{LiCl}$ hygrometer

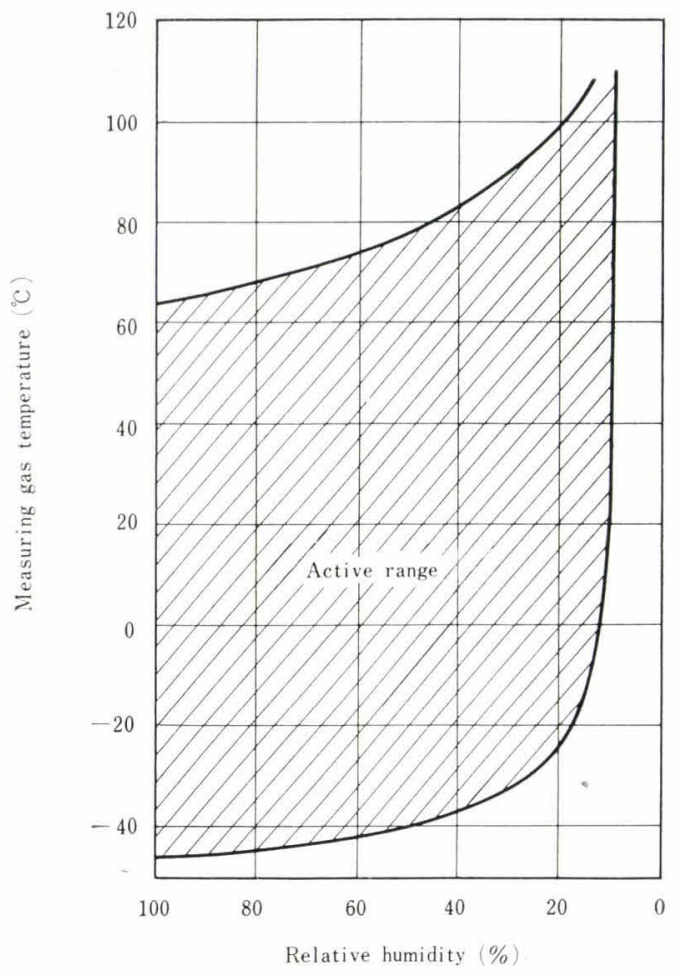

Fig. 6. Active range of $\mathrm{LiCl}$ hygrometer 
Primary wheels are driven by an induction motor and rotate at a constant speed. Secondary wheels are driven by a viscous torque which is the result of the rotation of the primary wheel. Torque ratio of the secondary wheels depends on the gas density ratio, as follows :

$$
\frac{T_{g}}{T_{a}}=\mathrm{C} \cdot \frac{\rho_{g}}{\rho_{a}}
$$

$T_{\eta}$ : Torque of secondary wheel in gas chamber

$T_{a}$ : Torque of secondary wheel in air chamber

$\rho_{q}$ : Measuring gas density

$\rho_{a}:$ Reference dry air density

Since the density change depends only upon the change in the moisture content, the humidity of the measuring gas can be known if it is blast air, by the

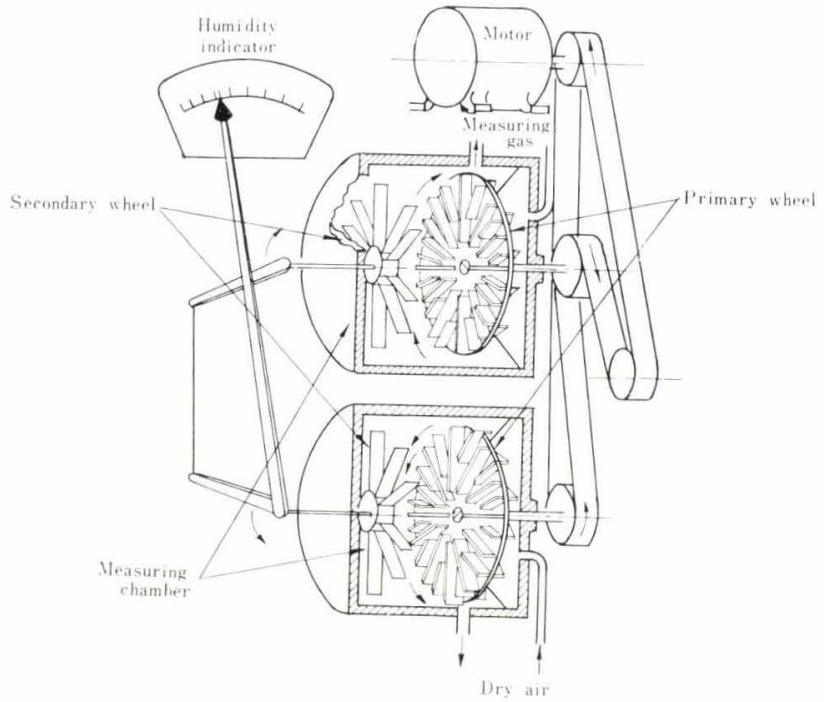

Fig. 7. Structure of gas density ratio type hygrometer torque ratio.

It is said on the basis of experiences in several steel plants that the weakness of this type of instrument is that the change in the density ratio value is too small in order to obtain sufficient accuracy for the humidity control:

Measuring time lag of this instrument is probably as follows :

$$
\begin{array}{ll}
\text { Time constant } & 20-25 \mathrm{sec} . \\
\text { Dead time } & 20-25 \mathrm{sec} .
\end{array}
$$

\section{Control System}

The most popular method for increasing the moisture content in the blast air is by steam injection into the blast air duct. Fig. 8 is a typical injection system ; steam is injected just after delivery from the blast air blower, and flowing through the orifice plate for measuring the rate of air flow, steam is mixed with the blast air thus raising its moisture content, then the humidity is measured before the inlet of hot stoves. According to the measured humidity values, the quantity of

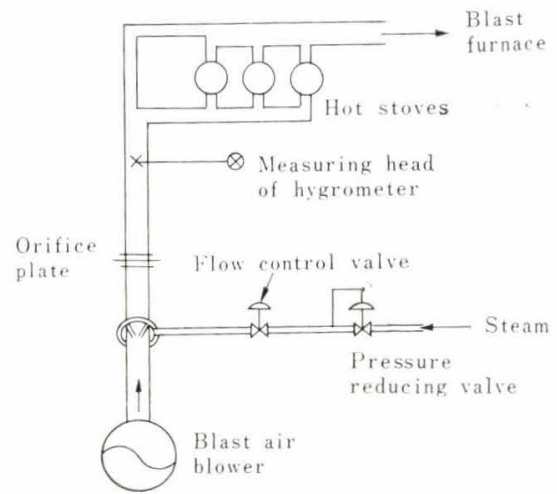

Fig. 8. Steam injection system of blast humidity control

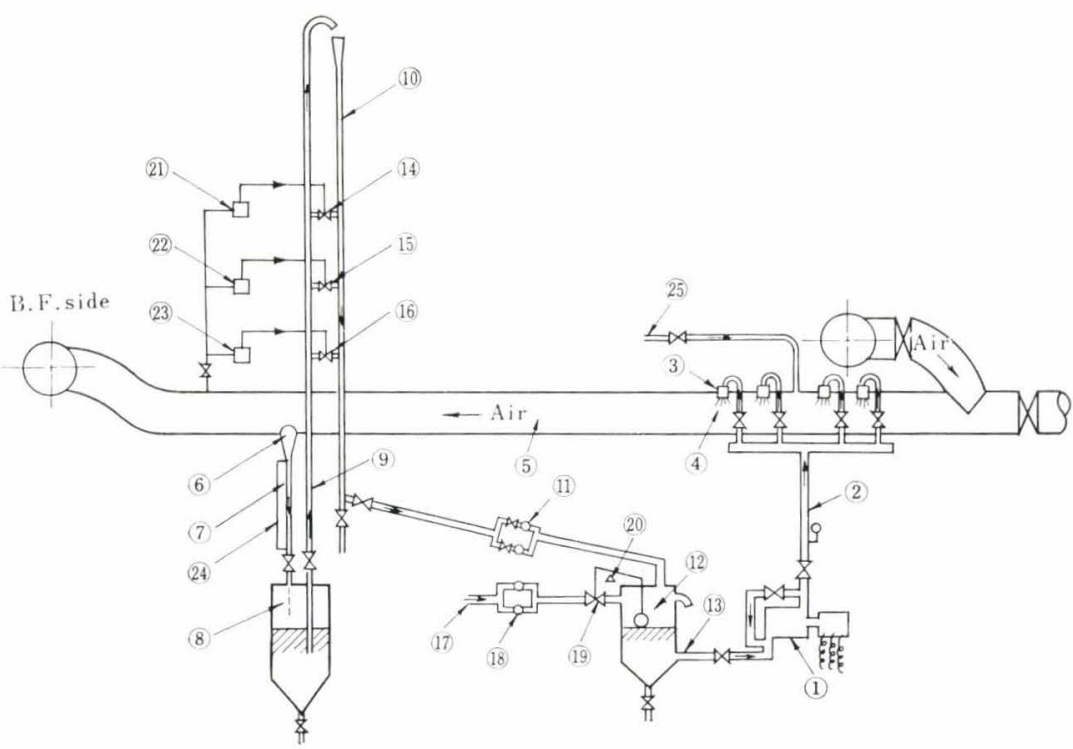

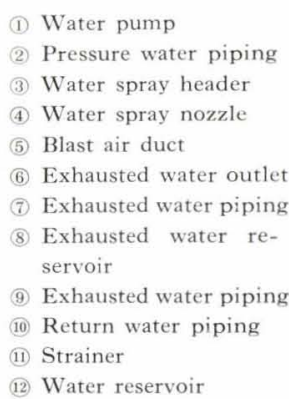

Fig. 9.

Water spray system developed by Yawata Iron \& Steel Co., Ltd. 
steam is controlled by the flow control valve - that is the method of humidity control.

Instead of steam, a water spray system has been developed by Yawata Iron \& Steel Co., Ltd. The detailed structure is shown in Fig. 9.

Atmospheric humidity is about $24 \mathrm{~g} / \mathrm{Nm}^{3}$ (gram per normal cubic meter) in summer and $4 \mathrm{~g} / \mathrm{Nm}^{3}$ in winter in Japan, and the changing speed is not so remarkable, for instance $1 \mathrm{~g} / \mathrm{Nm}^{3}$ per hour, $\pm 3 \mathrm{~g} / \mathrm{Nm}^{3}$ in a day, that it is not impossible to control the humidity manually with indicating instruments and remote control equipment. But it must be a very hard work for the operator, so generally automatic control systems are recom-

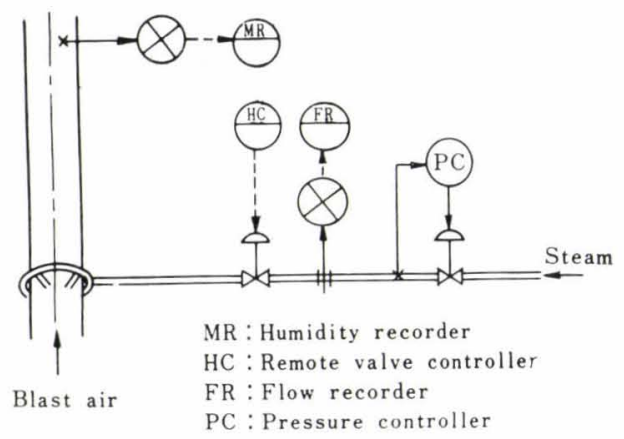

Fig. 10. Manual control system

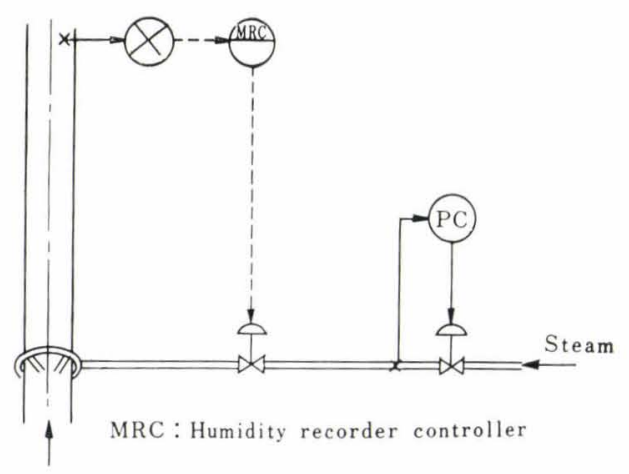

Blast air

Fig. 11. Direct type automatic control system

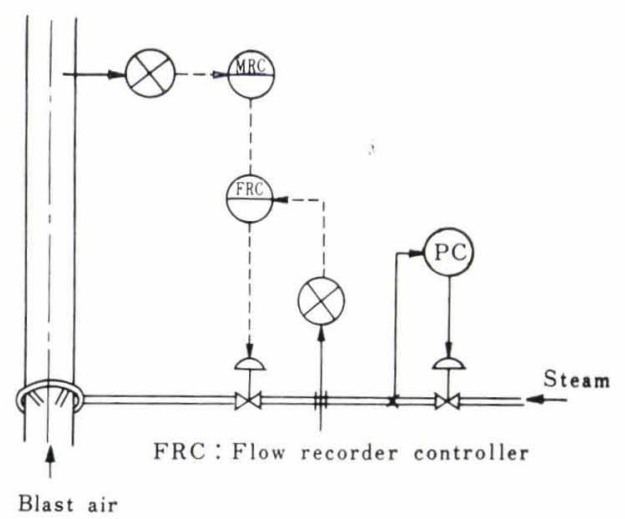

Fig. 12. Cascade type automatic control system mended.

Figs. 10-13 show a typical humidity control system.

Fig. 10 is a manual control system: observing the humidity recording instrument (MR) and the steam flow recorder (FR) in the control room, the operator controls the quantity of steam injected with the aid of a remote controller ( $\mathrm{HC}$ ).

Fig. 11 is a direct type automatic control system. In this case, the humidity recorder controller (MRC) controls a steam valve automatically according to the difference between the measured value and the setting value of the humidity.

Fig. 12 is a cascade type control system. In this system, output control signals of the humidity recorder controller(MRC) set the control point of the steam flow controller (FRC), which always regulates the steam flow automatically. Rapid disturbances are controlled by the flow controller (FRC) and slow disturbances are controlled by the humidity controller (MRC).

Fig. 13 is a latio-cascade control system. In this system, output signals of the MRC set the ratio control point of the blast air/steam. Since the control response is more rapid than other systems when the rate of flow of the blast air changes suddenly, this system is recommended for the blast furnace in which the blast flow

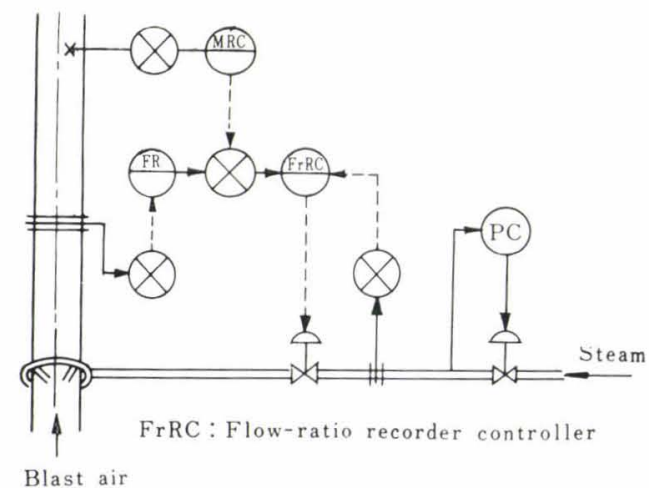

Fig. 13. Ratio-cascade type automatic control system

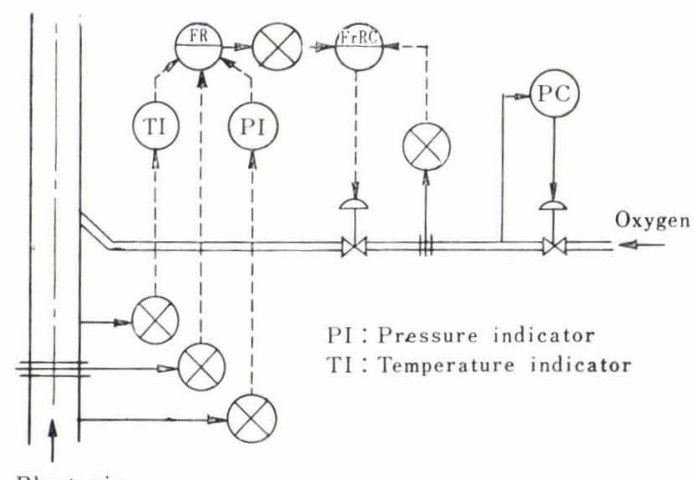

Blast air

Fig. 14. Oxygen enrichment control system 
rate setting is often changed.

All these control systems (Figs. 10-13) include a steam pressure controller (PC), but it is not necessary when steam pressure fluctuates only slightly or changes slowly.

A control system of oxygen enrichment is shown in Fig. 14. This is the automatic control system of the oxygen/blast air flow ratio. A temperature indicator (TI) and a pressure indicator (PI) are installed for automatic compensation of measuring the error in the blast air flow rate.

\section{Control Characteristics}

It has been known by investigations in the Instrumentation Division that a greater part of the control characteristics depend upon this sort of humidity measuring element.

\section{LiCI Type Control System}

Inditial response curves are shown in Figs. 15 and 16. Curves in Fig. 15 were observed when a step change was given to the input signal in the steam control valve of the cascade control system. Fig. 16 is a case when a step change was given to the setting point of the steam flow controller of the same control system. The humidity time constant in Fig. 15 is about 55 seconds and the dead time is about 30 seconds.

The steam flow rate and the humidity related to frequency responses and Bode's diagrams are shown in Figs. 17 and 18. This observation was made when a

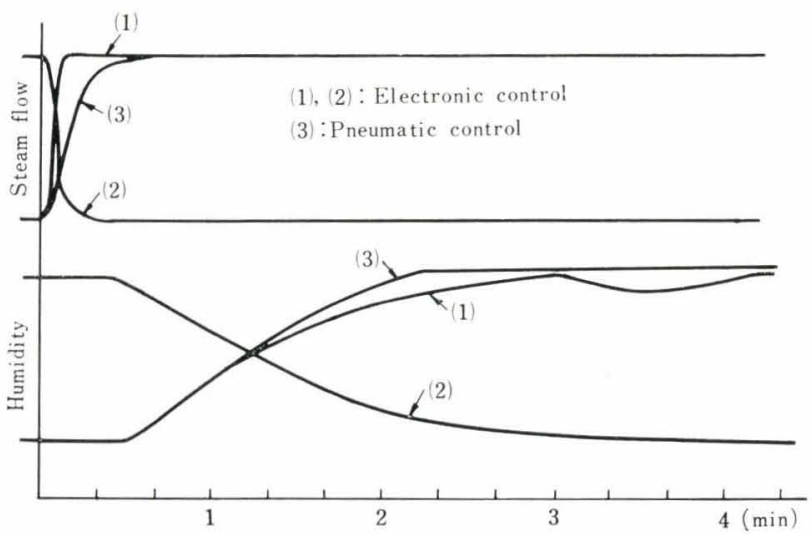

Fig. 15. Indicial response of $\mathrm{LiCl}$ control system (1)

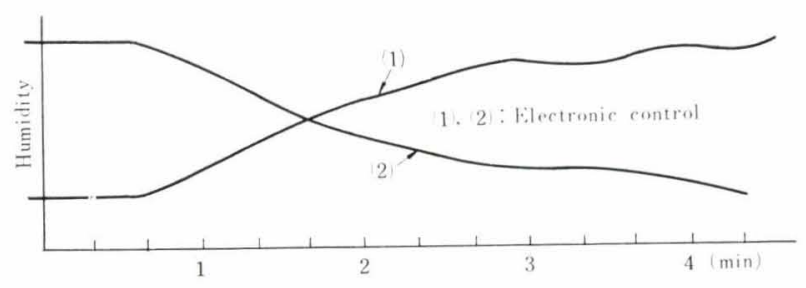

Fig. 16. Indicial response of $\mathrm{LiCl}$ cotrnol system (2) sine-curve change was given to the input signal in the steam flow control valve of the cascade control system.

The block diagram of this system as shown in Fig. 19 was made on the basis of the result obtained from the frequency response test. The transfer function of the LiCl measuring head was estimated as follows :

$$
G d=\frac{K e^{-2 S}}{(1+10 S)(1+25 S)(1+50 S)}
$$

\section{Wet and Dry Bulb Control System}

Indicial responses in Figs. 20 and 21 and frequency responses in Figs. 22 and 23 were made by the same methods as in the previous section.

The humidity time constant in Fig. 21 is about 30

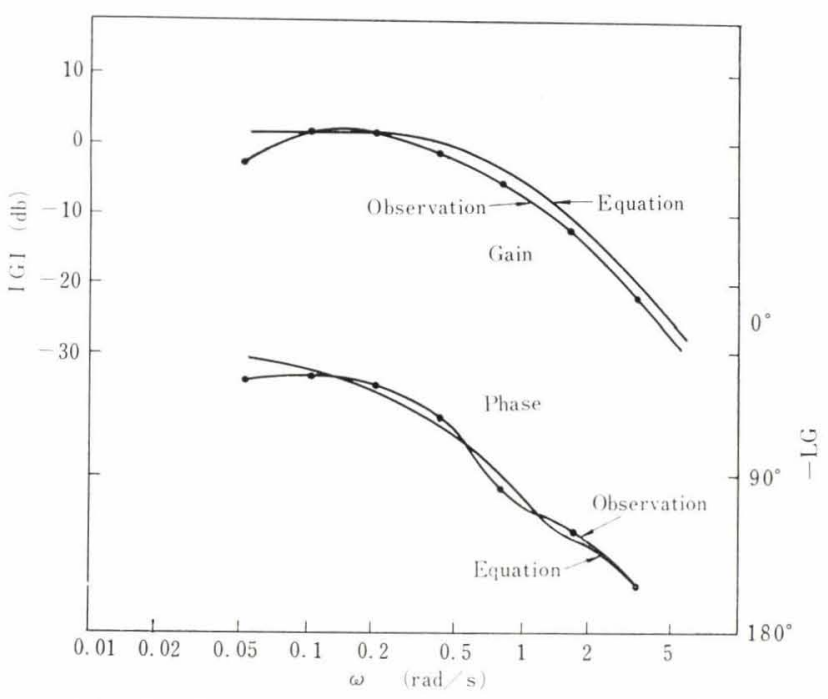

Fig. 17. Frequency response of steam flow in $\mathrm{LiCl}$ control system (electronic control)

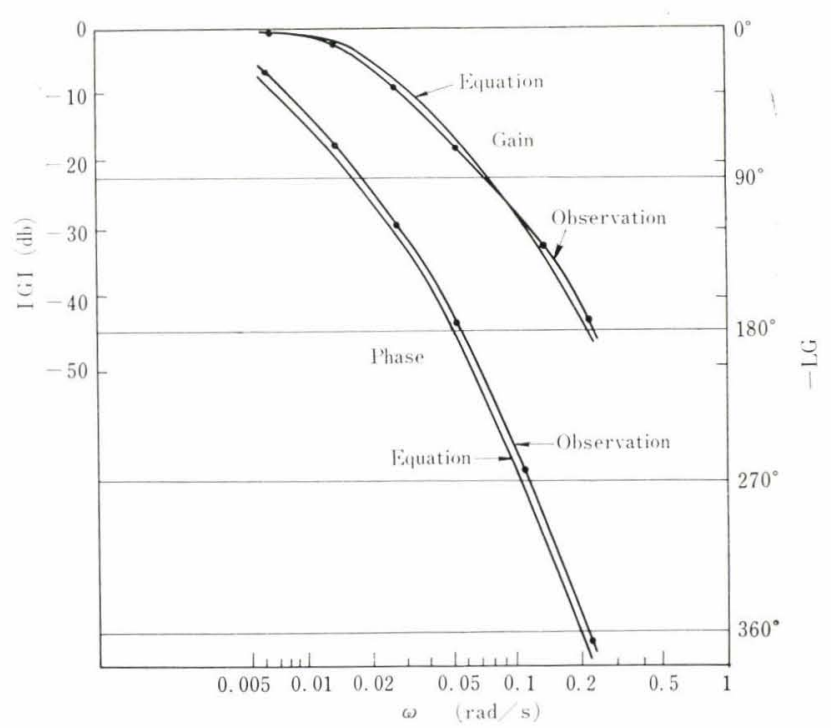

Fig. 18. Frequency response of humidity in $\mathrm{LiCl}$ control system (electronic control) 
50 seconds and the dead time is about 10 seconds.

The block diagram is shown in Fig. 24, and the transfer function is as follow:

$$
G d=\frac{e^{-4 S}}{1+28 S}
$$

The simulation of the wet and dry bulb control system was tried with an analog computer. A circuit diagram is shown in Fig. 25. Response curves in Figs. 26 and 27 were observed on the oscillograph when a step disturbance was given at (1) and (2) in Fig. 25. Such a simulation with an analog computer is a powerful method of investigating optimal settings in the automatic control system.

\section{Existing Systems}

Table 1 shows examples of the blast humidity control in Japan. As you see in this table, half are cascade control systems; 18 blast furnaces are of the cascade control type, 11 furnaces are of the direct type and 2 furnaces are of the manual control system.

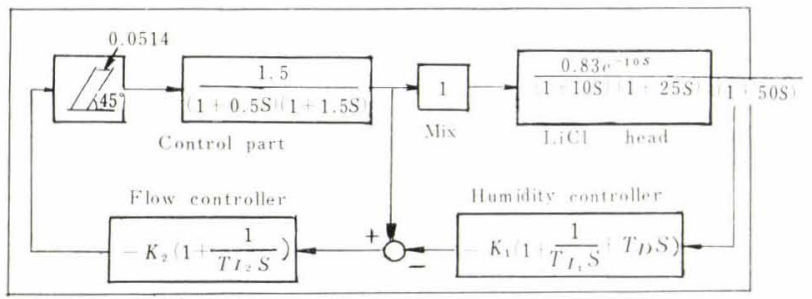

Fig. 19. Block diagram of $\mathrm{LiCl}$ control system

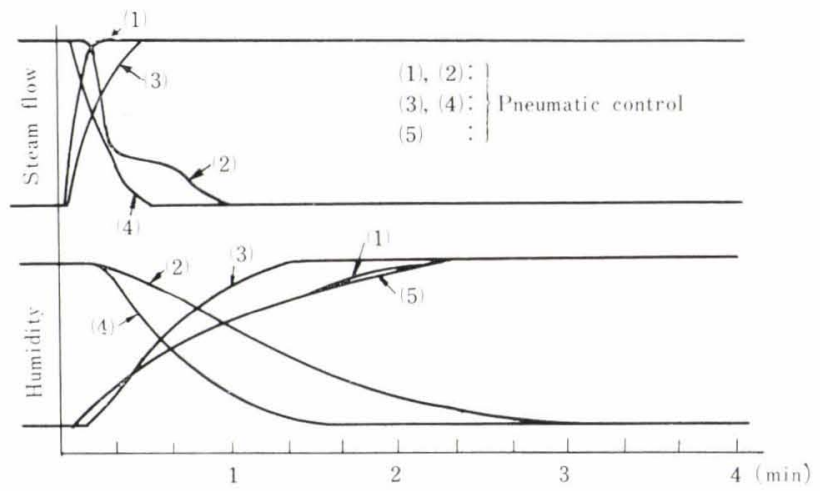

Fig. 20. Indicial response of wet and dry bulb control system (1)

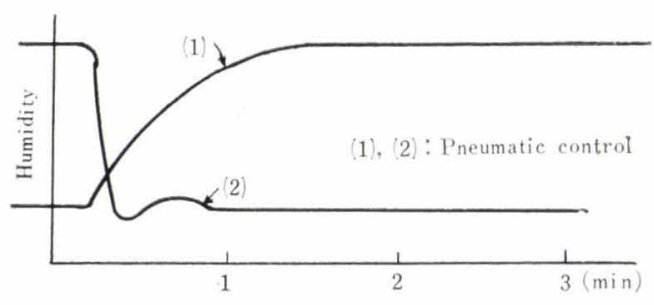

Fig. 21. Indicial response of wet and dry bulb control system (2)
As regards the measuring element, most of them use the LiCl elements: 24 furnaces are $\mathrm{LiCl}, 5$ furnaces are wet and dry bulb, and 2 furnaces are density-ratio type.

Five blast furnaces have installed the oxygen enrichment control together with the humidity control.

Fig. 28 is one of the existing $\mathrm{LiCl}$ type cascade control systems, which is installed at Kawasaki Works of Nippon Kokan Kabushiki Kaisha and Fig. 29 shows the structure of its sampling and measuring device. Various sampling and measuring devices have been designed as a result of diligent work in many steel works, and reported at the conference of the

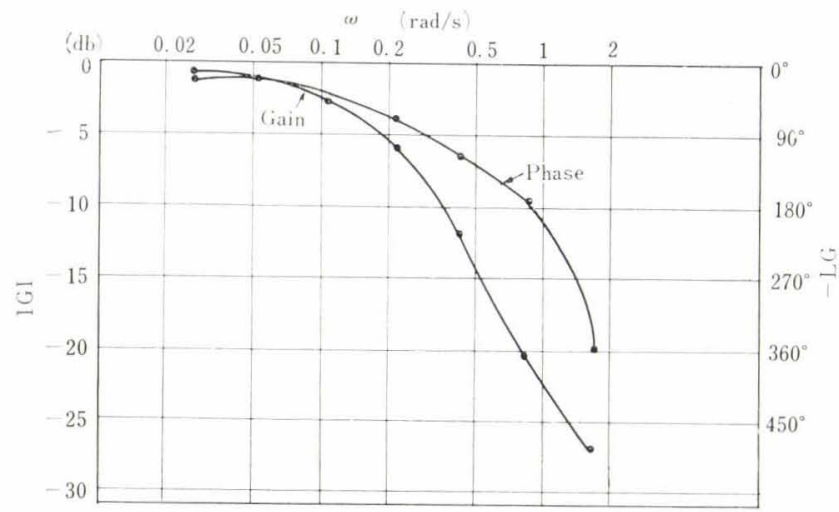

Fig. 22. Frequency response of steam flow in wet and dry bulb control system (pneumatic control)

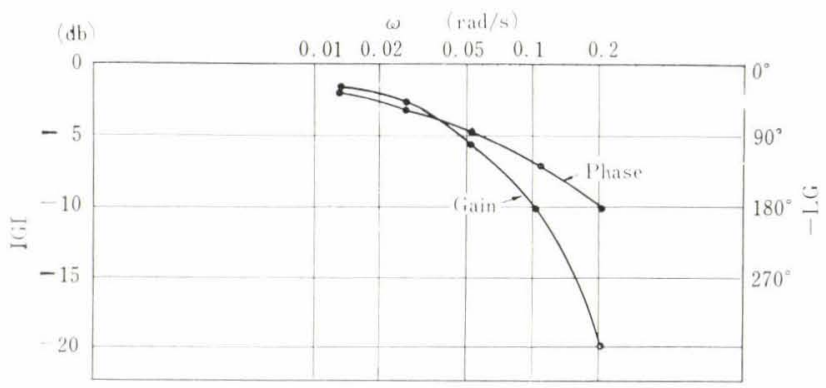

Fig. 23. Frequency response of humidity in wet and dry bulb control system (pneumatic control)

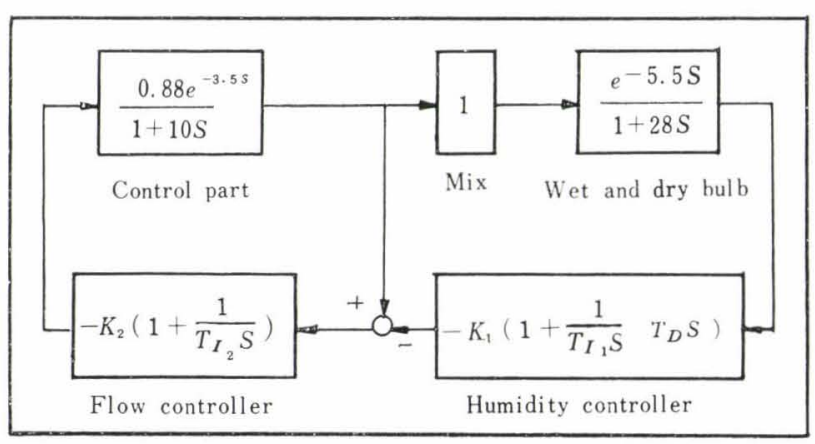

Fig. 24. Block diagram of wet and dry bulb control system 


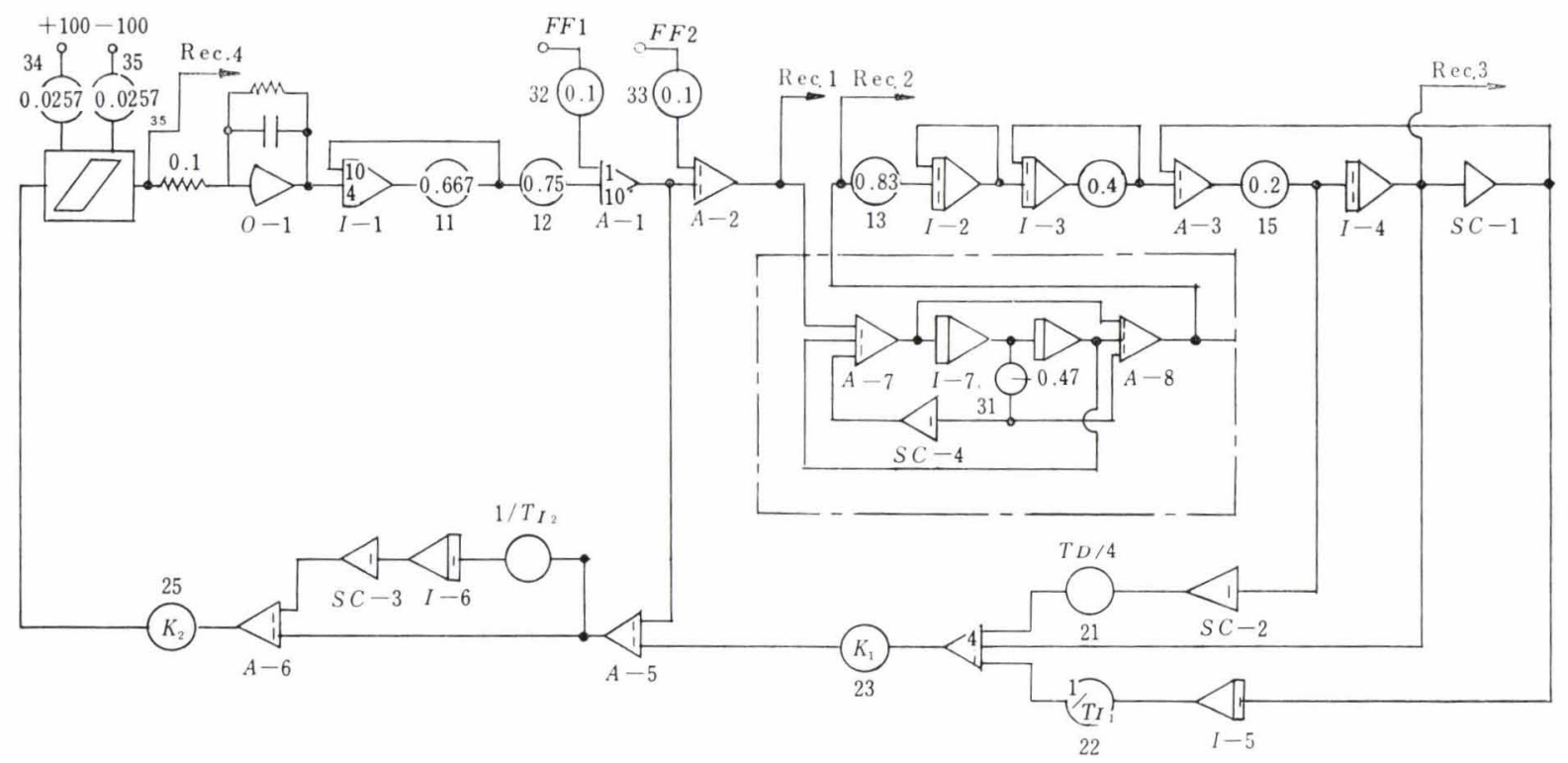

Disturbance

Fig. 25. Circuit diagram of an analog computer

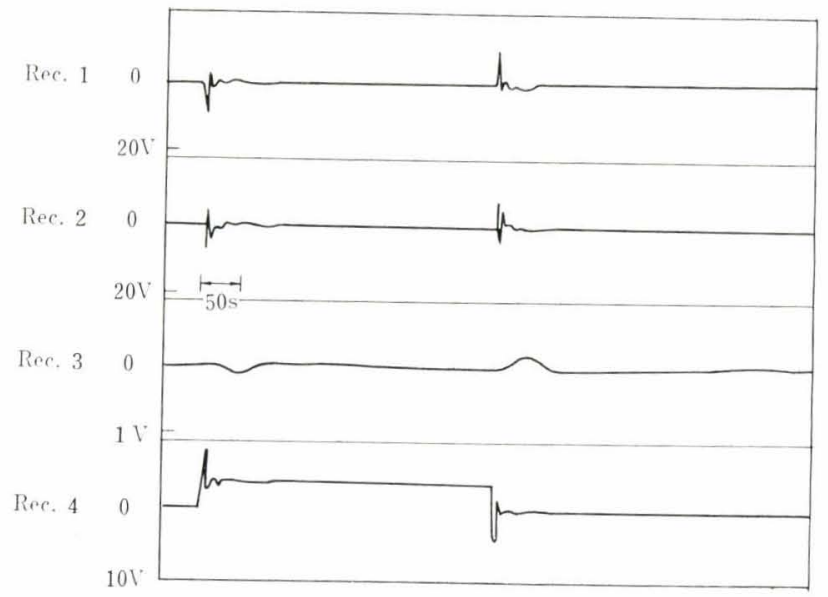

Fig. 26. Responses against step disturbance (1)

Instrumentation Div.

Figs. 30, 31, 32 and 33 are examples of these sampling and measuring devices which have been made at Yawata Iron \& Steel, Fuji Iron \& Steel, Kawasaki Steel and Sumitomo Metal. Every one of these devices has a noticeable feature and all of them are usable, but as yet the authors have no predilection. In fact, an improvement on the weak points of the existing structure is thought to be the most important and urgent problem at the moment.

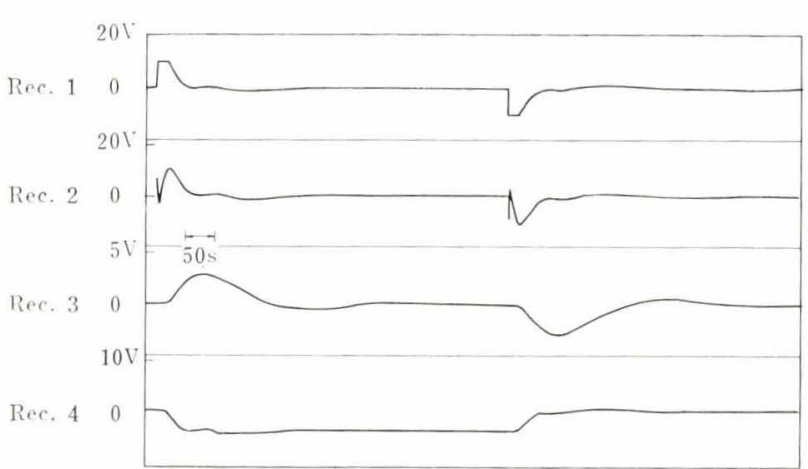

Fig. 27. Responses against step disturbance (2)

Fig. 34 is an example of the wet and dry bulb type direct control system, installed at Kamaishi Works of Fuji Iron \& Steel and Fig. 35 is a manual control system of Nakayama Steel.

The authors have had many reports and discussions about developments and improvements of actual equipments, advices about constructions, maintenance problems, control results, trouble statistics, etc. To their regret the authors can not describe all of them, but they want to make a description of the profitable results picked up from them.

Sumitomo Metal (Kokura Works) - As a result of the humidity 
Table 1. List of humidity controlled blast furnaces

Humidity controlled blast furnace

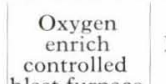
controlled
blast furnace

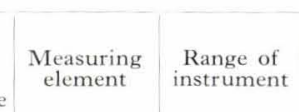

$\begin{gathered}\text { Measuring } \\ \text { element }\end{gathered}$
$\begin{gathered}\text { Range of } \\ \text { instrument }\end{gathered}$
Control system
Yawata Iron \& Steel, Higashida, 3, 4, 5, 6 BF Kukioka, 2 BF

Tobata, 1, 2 BF

Fuji Iron \& Steel, Muroran, 1, 2, 3 BF

$$
, \quad 4 \mathrm{BF}
$$

Kamaishi, 1 BF

Hirohata, 1 BF

$$
\text { , } 2 \mathrm{BF}
$$$$
\text { , } 3 \mathrm{BF}
$$

Nippon Kokan, Kawasaki, 2, 3, 4, 5 BF

Tsurumi, $1 \mathrm{BF}$

$$
, \quad 2 \mathrm{BF}
$$

Kawasaki Steel, Chiba, 2, 3 BF

Sumitomo Metal, Kokura, 2 BF

Wakayama, $1 \mathrm{BF}$

Kobe Steel, 1 BF

Amagasaki Iron \& Steel, 1 BF

$$
2 \mathrm{BF}
$$

Nakayama Steel, 1 BF

$$
2 \mathrm{BF}
$$

Osaka Steel, 1BF

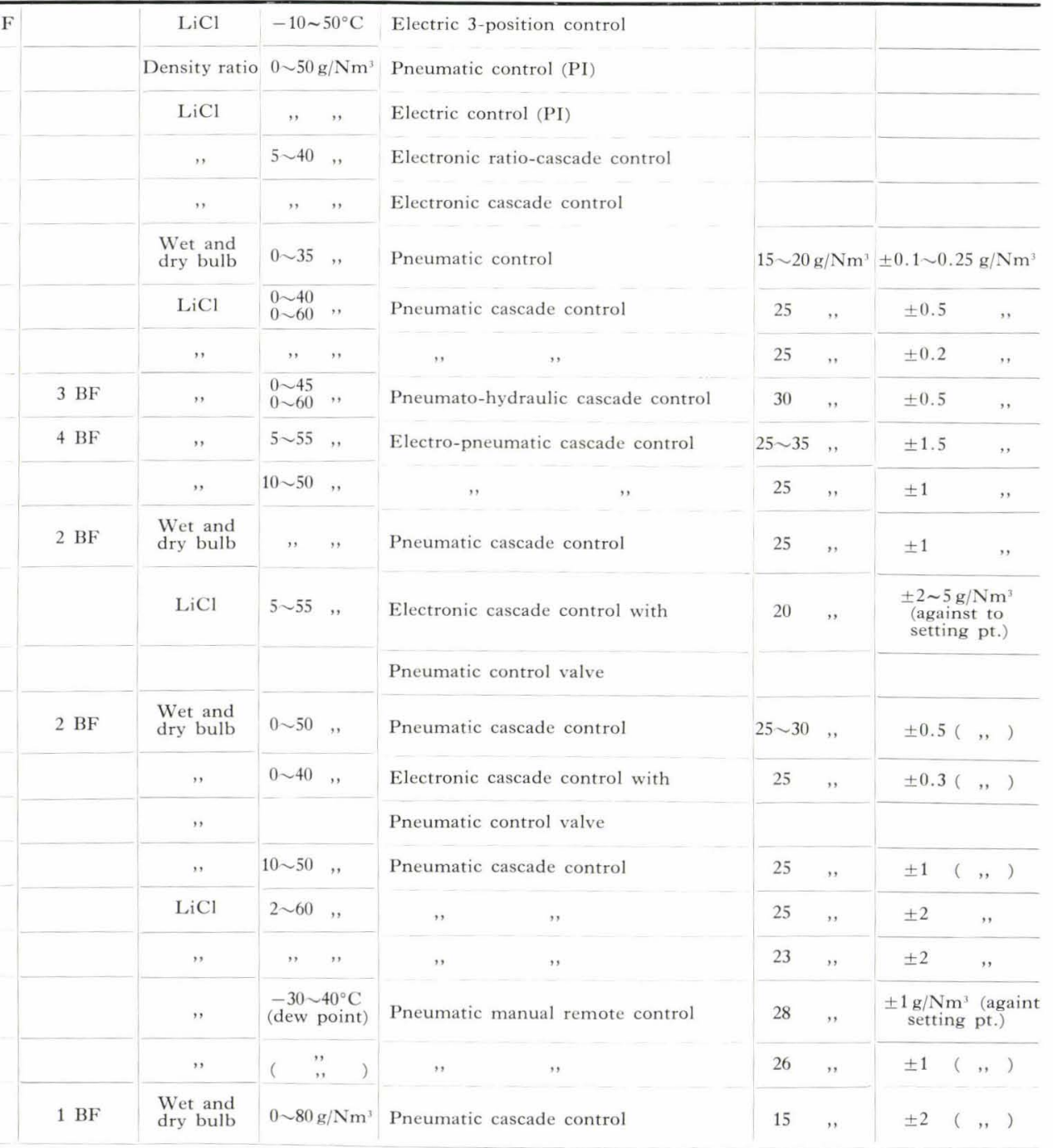

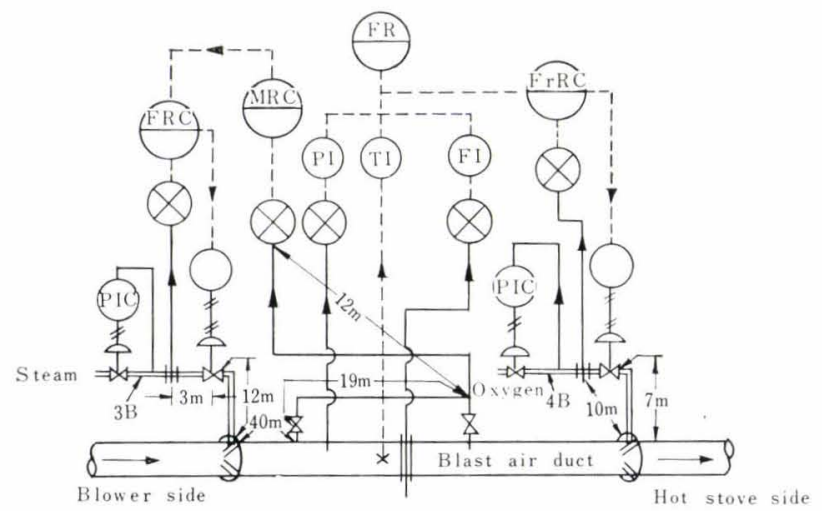

PIC: Pressure indicator

Fig. 28. LiCl type humidity control system at the Kawasaki Works, Nippon Kokan K. K.

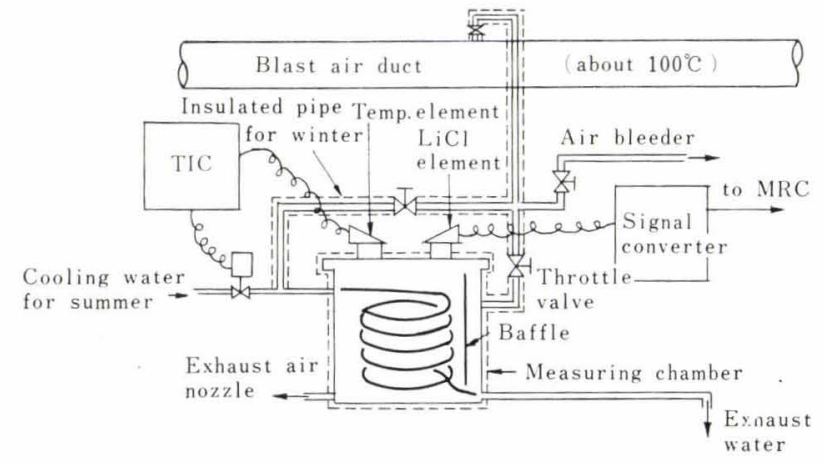

TIC: Temperature indicator controller

Fig. 29. Structure of sampling and measuring device ( $\mathrm{LiCl}$ type) at the Kawasaki Works, Nippon Kokan K.K. 
control, getting a good stable furnace condition, coke ratio decreased about $1 \mathrm{~kg} / \mathrm{t}$ of pig iron, and the production rate of pig iron increased about $2.5 \mathrm{t}$ /day against to increasing $1 \mathrm{~g} / \mathrm{Nm}^{3}$ of humidity.

Nippon Kokan (Tsurumi Works) - Yield of pig iron has increased about $5 \%$, coke ratio getting lower, qualities of pig iron have improved.

Amagasaki Iron \& Steel-Getting good furnace condition, chances of hanging or slipping have lessened, could raise the blast temperature from $800^{\circ}$ to $1,000^{\circ} \mathrm{C}$, coke ratio decreased from 0.7 to 0.55 , and yields of pig iron have increased and qualities of it have become more uniform.

Nippon Kokan (Kawasaki Works) - Chances of hanging and slipping have lessened, and the coke ratio has decreased, but can not be said quantitatively.

Yawata Iron \& Steel (Yawata Works)-It has been very effective in controlling furnace conditions.

Fuji Iron \& Steel (Kamaishi Works) - When hanging occurred,

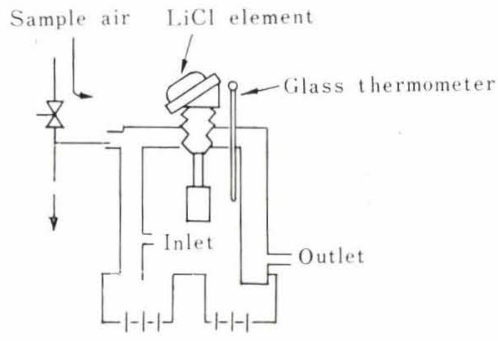

Fig. 30. Sampling and measuring device ( $\mathrm{LiCl}$ type) at the Higashida Works, Yawata Iron \& Steel Co., Ltd.

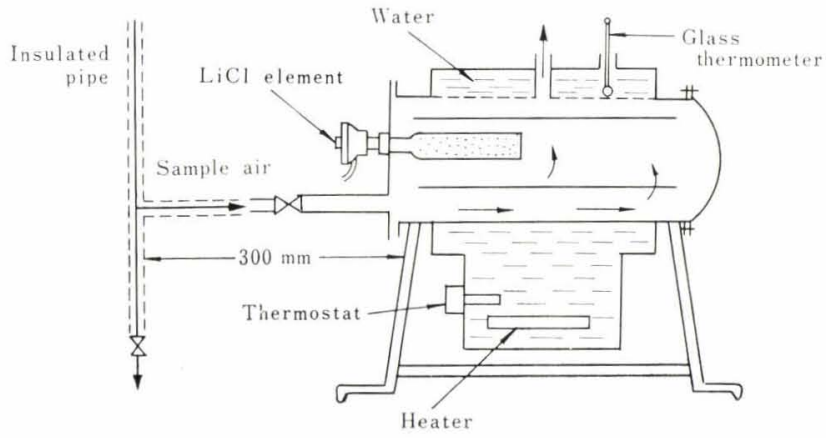

Fig. 31. Sampling and measuring device ( $\mathrm{LiCl}$ type) at the Chiba Works, Kawasaki Steel Corporation

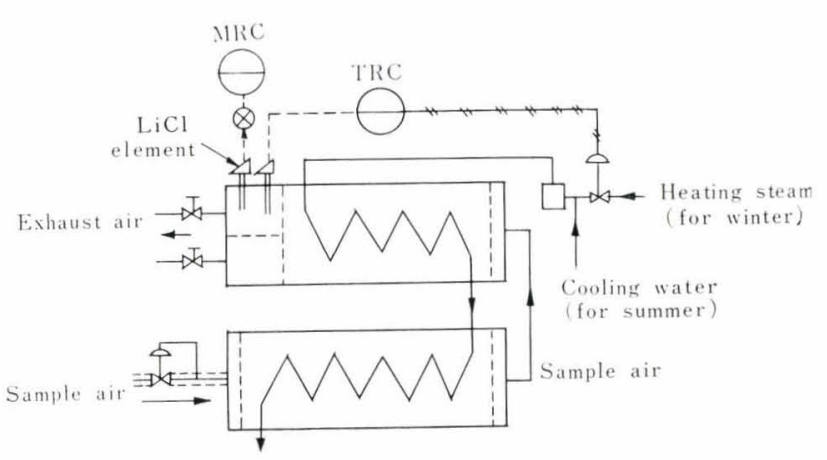

Fig. 32. Sampling and measuring device ( $\mathrm{LiCl}$ type) at the Hirohata Works, Fuji Iron \& Steel Co., Ltd. they could lead the furnace condition to a stable state by heavily adding steam with the aid of a humidity control system.

Kawasaki Steel (Chiba Works) - Yield rate shows a tendency to increase, but can not be said quantitatively.

Kobe Steel-Getting stable furnace condition, operations have become smooth.

\section{Maintenance}

Maintenance is an important problem in order to keep a good control state. Table 2 shows the standard maintenance items of the $\mathrm{LiCl}$ type humidity control

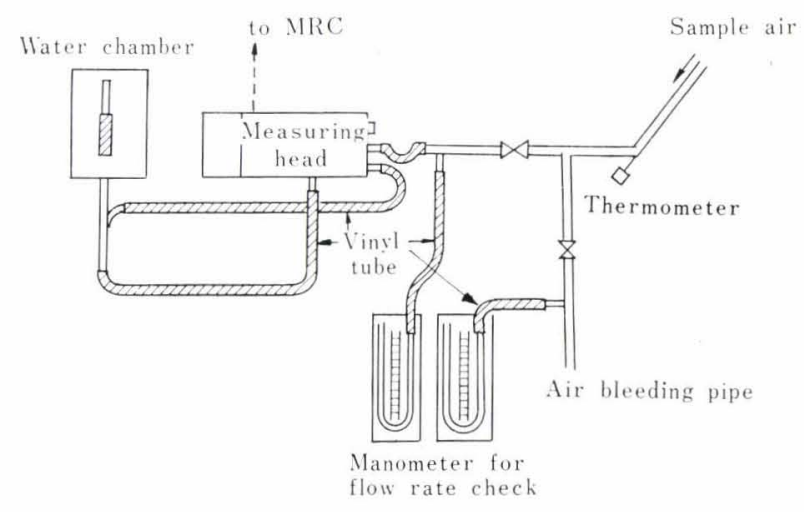

Fig. 33. Sampling and measuring device (wet and dry bulb type) at the Kokura Works, Sumitomo Metal Industries, Ltd.

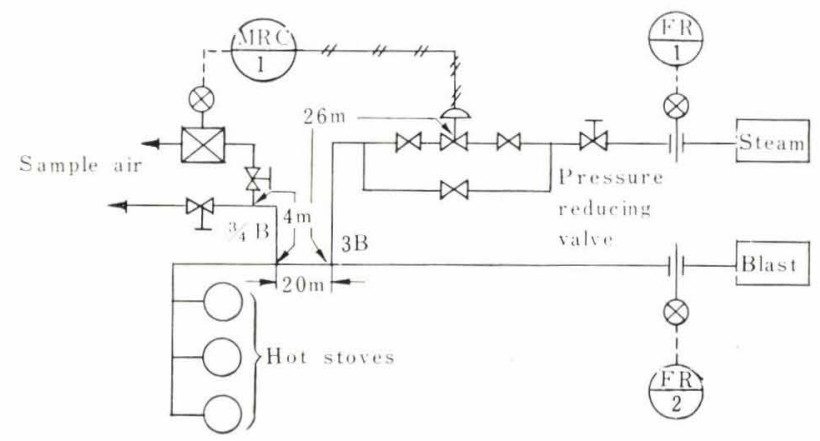

Fig. 34. Wet and dry type humidity control system at the Kamaishi Works, Fuji Iron \& Steel Co., Ltd.

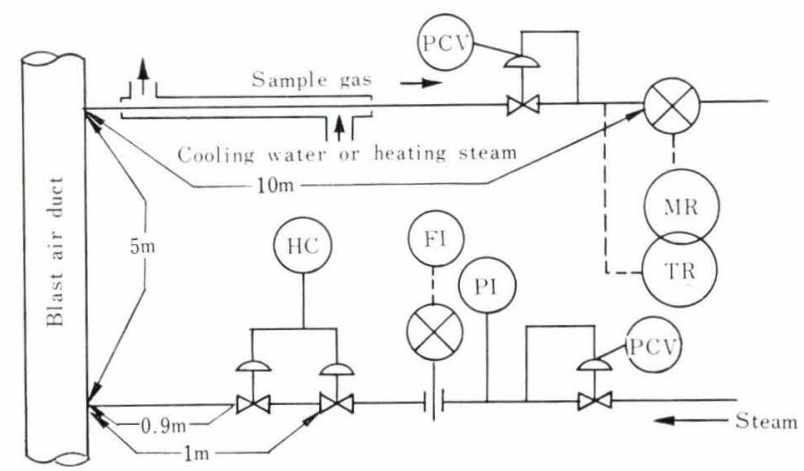

Fig. 35. Manual control system of Nakayama Steel Works, Ltd. 
Table 2. Standard maintenance items ( $\mathrm{LiCl}$ system)

\begin{tabular}{l|c}
\multicolumn{1}{c|}{ Maintenance item } & Frequency \\
\hline Sampling and measuring device & \\
Repainting of $\mathrm{LiCl}$ solution & $1 / \mathrm{m}$ \\
Check of sample gas temperature & $1 / \mathrm{d} \sim 3 / \mathrm{d}$ \\
Check of sample gas flow quantity & $1 / \mathrm{d} \sim 3 / \mathrm{d}$ \\
\hline Instrument & \\
Check of indicated value & $1 / \mathrm{w}$ \\
Check of operating state of instrument & $1 / \mathrm{d}$ \\
\hline
\end{tabular}

equipments.

Here $1 / \mathrm{m}$ is once a month, $1 / \mathrm{w}$ is once a week and $1 / \mathrm{d}$ is once a day.

This table is made about items peculiar to the humidity control, but general maintenance items about ordinary recording instruments, control valves and other general purpose equipments, are neglected.

Repainting of $\mathrm{LiCl}$ solution is an important item. In case the blast air contains a lot of oil particles, it is necessary to repaint it more frequently.

Temperature of sample gas must always be maintained higher than the dew point and in the active range shown in Fig. 6.

Flow speed of sample gas should be controlled as not to exceed $0.25 \mathrm{~m} / \mathrm{sec}$ in the measuring chamber.

Table 3 shows the standard maintenance items of wet and dry bulb type control equipments.

When the cotton gauze, wrapped on the wet bulb, becomes dirty, evaporation of water is prevented, and as a result the response speed is decreased. So, it is necessary to change the gauze periodically.

Fresh water must be supplied to the measuring chamber, and it has to keep the state such that a
Table 3. Standard maintenance items (wet and dry bulb system)

\begin{tabular}{l|c}
\multicolumn{1}{c|}{ Maintenance item } & Frequency \\
\hline Sampling and measuring device & $1 / \mathrm{w}$ \\
Change of cotton gauze & $1 / \mathrm{d} \sim 3 / \mathrm{d}$ \\
Check of water supply & $1 / \mathrm{d} \sim 3 / \mathrm{d}$ \\
Check of sample gas temperature & $1 / \mathrm{d} \sim 3 / \mathrm{d}$ \\
Check of sample gas flow quantity & \\
Instrument & $1 / \mathrm{w}$ \\
Check of indicated value & $1 / \mathrm{d}$ \\
Check of operating state of instrument &
\end{tabular}

small amount of water is constantly supplied into the water chamber in the measuring head, and constantly overflows from it.

Temperature of the sample gas must be kept higher than the dew point, and its flow speed must be higher than $3 \mathrm{~m} / \mathrm{sec}$ in the measuring chamber.

At any rate, it is very important that maintenance works are put in operation according to the established standard maintenance tables.

\section{Conclusions}

This report makes mentions of the blast humidity control on the basis of the activities of the Instrumentation Div., the Joint Research Society.

Instrumentation and control of the blast furnace have been the main theme on conferences of the Instrumentation Div. recently, and it is expected to issue reports, "Top Gas Analysis of Blast Furnace" and "Automatic Control of Hot Stoves" in the near future. 